\title{
CONSERVATION OF NATURAL RESOURCES*
}

\author{
By C. H. Desch, F.R.S.
}

$\mathrm{T}$ HE natural resources of the world fall into two main groups. The one, represented by the products of agriculture and forestry, may be renewed, either annually or at longer intervals, by cultivation, and may be consumed as income, while the other, including mineral wealth, must be regarded as capital, and once consumed is not renewed. Soils should perhaps form a third category, for while they may be maintained in fertility for thousands of years, as in China, they are only too easily ruined by careless or greedy exploitation, leading to exhaustion and erosion, or by mining operations, which may cause subsidence as in parts of England, or burial under debris through hydraulic mining as in California. This paper is mainly concerned with the conservation of those mineral resources on which modern industrial civilization increasingly depends.

Mineral deposits have too often been regarded as inexhaustible, and it is only lately that the possibility of exhaustion in a measurable time has attracted attention. As industrialization becomes more intense in Western societies and continually extends to regions which were purely agricultural, the rate of consumption of mineral capital is sccelerated to an extent which is not always appreciated. Sir Thomas Holland has shown that in the first twenty-five years of the present century the quantity. of minerals extracted from the earth was greater than that raised in the whole previous history of the world, or, say, six thousand years since copper was first mined. A report to a committee of the League of Nations in 1937 by Prof. Högbom gave diagrams which showed that over a period of about sixty years the annual production of coal doubled itself in a little less than seventeen years, of pig iron at about the same rate, of oil in eight and a half years, of copper in twelve and a half years, and of tin in eighteen years, the general trend remaining remarkably constant in spite of temporary fluctuations. Coal, for reasons which have been given by Sir Harold Hartley, ceased to increase after 1913, but in most instances, after an initial rate of growth which may be irregular, as for aluminium to-day, a stable rate is reached which gives a straight line when plotted logarithmically.

This does not mean that the production in any one country follows this law. The older producing regions may show a slower rate of increase, but

* Paper read at the Conference on Science and World Order on September 27. this is compensated for by the opening up of new sources as the demand grows. It may seem impossible that such a fantastic rate of growth could long be maintained, but the standard of living which calls for such a consumption of metals and power applies as yet only to the Western nations. China consumes little metal, its enormous population depending on the use of renewable natural wealth rather than on mineral capital, but it represents a vast potential consumption, and the same may be said of India and, perhaps in a more distant future, of Africa.

It is extremely difficult to form an estimate of the existing mineral reserves. The total quantity of each element in the earth's crust, down to a certain fixed depth, has been estimated with some accuracy, and the figures are surprising. Nickel proves to be ten times more abundant than lead and fifty to a hundred times more than tin. Vanadium is more abundant than copper. But it by no means follows that they can be recovered in those proportions. For the most part, metals are very finely disseminated in the rocks, and extraction is only possible where local concentration has occurred through geological causes. Nearly 90 per cent of the world's nickel comes at present from a single great deposit in Ontario, and there are few other important sources. The deposits of tin are also highly local. The concentration which is necessary for profitable working varies very widely; thus the ore of the Rand may be worked when it contains one part of gold in 150,000 , while hydraulic mining has been used on deposits containing only one part of gold in three millions. On the other hand, an ore containing 20 per cent of iron is of low grade.

The estimates of world mineral reserves given by standard authorities fluctuate from year to year, but there is a certain complacency in the statement regarding some important minerals that the reserves will last for several decades. Where essential capital, which there is no possibility of replacing, is concerned, we have to consider a more distant future. It appears that coal and iron may last for several thousand years, but the known reserves of oil, gold, tin and perhaps copper suggest a life of less than a century. That life may be extended in two ways : by the discovery of new deposits, or by improvements in methods of mining and extraction. The first is always possible, and there are regions such as the mass of ancient rocks in Canada still covered by 
forest which may prove to be valuable, but the areas unsurveyed are constantly dwindling, and there are vast regions which are mineralogically barren. By far the greater part of the mineral production of the world comes from countries bordering the North Atlantic, and ore deposits of importance are limited in the main to the fringes of the great oceans and a few mourtain ranges.

It is, however, possible to improve greatly the methods of mining and of concentration. To take the latter first, the enrichment of sands and crushed rocks by mechanical separation is as old as mining itself, but it has been greatly perfected in the last century, and the introduction of new physical methods, such as magnetic separation, froth flotation (depending on surface tension) and electrolysis have made possible the working of ores of low grade. Further inventions of this kind may revolutionize the extraction of minerals, and in that case the estimates of the life of deposits now accepted may be too pessimistic.

Improvements in mining may make it possible to extract a larger proportion of the useful material from a given deposit, and this seems particularly likely in the case of oil, but it must be remembered that mining operations are usually wasteful. The extraction of the rich ore from a mine frequently renders inaccessible a larger quantity of ore of lower grade which it does not pay to bring to the surface. Under the usual conditions of exploitation there is a natural tendency to 'skim the cream' from a deposit, extracting only that material which is immediately profitable, and this is most likely to occur where a concession is being worked, perhaps in a politically unstable country, by a foreign company. This is one of the factors to be taken into account in a scheme for an international control of raw materials.

Each new technological advance is apt to create a fresh demand for some material, which may be of scanty occurrence. . The electrical industry is much dependent on the unique qualities of certain varieties of mica, and the engineering industries call for steels and other alloys containing the rarer elements, such as nickel, tungsten, molybdenum, cobalt and vanadium. The light alloy industry is of very recent origin and has opened up great new fields of usefulness, and this again will in future make greater use of some of the rare elements. Little is known as to the available reserves of these metals, but the deposits containing them are usually small and are highly local. Some of them must be within measurable distance of exhaustion.

One possible mineral source as yet but little explored may be mentioned in passing. Owing to the disintegration of rocks by weathering and the transport of the products by water, all the elements present in the rocks are found in the sea. It is true that they are in an extremely dilute state, but recovery is not impossible. The fiasco of 'gold from sea water' of some years ago may seem to make this unlikely, but modern physical chemistry suggests possible means of concentration. Already magnesia is recovered from sea water in quite large quantities, the great volume of water which has to be handled not proving an obstacle.

Most minerals, once extracted from the earth, find application in industry, and after a period of usefulness which may be long or short become waste. Some of them, but not all, return in part in the form of scrap. Steel is made from pig iron, and until 1914 the world's production of pig iron was greater than that of steel, the balance being used in the foundry. In 1914 the curves crossed, and since then the production of steel has been greater, and increasingly so, than that of pig iron, owing to the very large quantities of scrap which are returned to the steel furnace. Not all of it comes back, corrosion and waste accounting for a considerable proportion. The use of recovered or 'secondary' metal, as it is called, is also becoming important in other metal industries, such as that of aluminium. Unfortunately, the key elements used in small quantities in alloy steels are largely lost, and it is here that a shortage is soonest likely to be experienced. Research is needed to devise means of recovering these essential and irreplaceable materials when the objects which contain them become scrap.

Much is now heard of substitutes for materials which have become scarce, and in Germany especially great efforts have been made to reduce to a minimum the quantities of metals used, such as nickel and tin, which cannot be produced at home, but it cannot be said that any startling success has been obtained in this direction. The new field of plastics offers genuine substitutes for metals for a variety of purposes, and as some of them can be manufactured from agricultural products they represent a real contribution to the cause of conservation.

There is one instance of a mineral which has been almost entirely replaced by an artificial product. Chile nitrate, for long the only source of artificial nitrogenous fertilizers, and occurring only in certain rainless districts of South America, where it had been formed under quite exceptional geological conditions, was clearly limited in its reserves, and its exhaustion could be foreseen. In $1898 \mathrm{Sir}$ William Crookes, in a famous address to the British Association, painted an alarming picture of a decline in the supply of wheat owing to the exhaustion of soil nitrogen. Nitrogen compounds synthesized from the air have now replaced Chile nitrate, and the supply of them is inexhaustible. Radium, the 
ores of which are very rare, is being supplemented for medical and similar purposes by artificial radioactive elements, but substitutions of this kind are obviously very exceptional In the main, we can only look to a more economical use of metals and to more complete recovery as a means of conservation. Another fertilizer, phosphate, is mainly derived (apart from that which is a byproduct of the basic steel industry) from a few sources of limited extent, and our present highly inefficient means of dealing with sewage leads to the greater part of the phosphates being discharged into the sea. This is a form of waste which is closely linked with the general question of the fertility of the soil, and the problem will call urgently for a scientific solution in the very near future.

The case for a planned conservation of mineral resources may not seem so strong as that for energetic action to conserve soils and forests. Even minerals of which the known reserves are small may last for several generations. The future of the rarer and increasingly important elements is more difficult to foresee because of the imperfect survey so far made of their scattered deposits, but it is likely that the demand for them will increase more rapidly than that for the more common minerals. However, many of the errors of the past have come from lack of foresight, and a planned world economy must take account of conditions a century or more hence, when our descendants may find themselves hampered by the wasteful exploitation of natural resources in our own day.

That an international control of raw materials will be needed after the War is a natural consequence of such a promise as that of equal access contained in the fourth aim of the Atlantic Charter. A recent issue of Planning (P E P) has suggested a means by which such a control could be introduced, tentatively àt first by application to a small number of commodities, the international raw materials union of producers including representatives of Governments in their capacity of consumers as well as producers. Such an authority would have many functions outside the scope of this paper, but as it would be in possession of the fullest information as to production, consumption and reserves it would be able to consider, in the light of that knowledge, the question of the possible exhaustion of reserves, and to recommend, or if its constitution should permit, to enforce, greater economy in use or a restriction of exploitation.

\section{ECONOMIC ASPECTS OF THE BLOCKADE AND COUNTER-BLOCKADE}

\section{By Paul Einzig}

$\mathrm{T}$ HE relative importance of the economic factor among the factors determining the outcome of the War has increased considerably as a result of the progress in the mechanization of the armed Forces. Requirements of weapons and equipments of raw materials necessary for their manufacture and of motor fuel are now incomparably larger and more diversified than they were during the War of 1914-18. The striking power of the armed Forces is now dependent on the industrial capacity and the importing capacity of the belligerent countries to a much higher degree than in previous wars. The belligerent countries are now incomparably less self-sufficient than they were in the past. For this reason the duration and outcome of the present War depends to a very large extent on the results of blockade and counter-blockade.

It is essential to avoid exaggerating the relative importance of economic warfare; but it is equally important to avoid going to the other extreme. The exaggeration of the relative importance of the blockade during the early months of this War was largely responsible for the slackness of Great
Britain's war effort in other directions during that period. After the disillusionment that followed the German victories in Western Europe, the pendulum swung in the opposite direction, and for some time it was all but generally believed that economic warfare in general and blockade in particular was incapable of producing any noteworthy results. The truth lies somewhere half-way between the two extremes. In order to defeat Germany it is indispensable to win a decisive military victory. Such a victory is inconceivable, however, unless and until Germany's vital economic resources have been materially reduced as a result of offensive economic warfare. It is an equally essential condition of victory that offensive economic warfare waged by Germany in the form of counter-blockade and air bombing should be prevented from reducing Great Britain's economic resources.

The argument of those who underrate the importance of offensive economic warfare among our weapons against Germany runs broadly as follows :

The relative extent to which Germany's economic resources can possibly be affected either by air 